Revista Eletrônica de Estudos Integrados em Discurso e Argumentação ISSN 2237-6984

\title{
Stickers do Whatsapp: (nova) forma persuasiva de interação bem-humorada
}

\section{Ana Cristina Carmelino}

Docente da Universidade Federal de São Paulo (UNIFESP), Brasil.

anacriscarmelino@gmail.com

\section{Lídia Kogawa}

Graduanda em Letras pela Universidade Federal de São Paulo (UNIFESP), Brasil.

lidiakogawa@yahoo.com.br

Resumo: Com base especialmente nos pressupostos teóricos da Retórica e da Nova Retórica, pretendemos, neste artigo, refletir a respeito de como certas "figuras" usadas na interação via WhatsApp, que ficaram conhecidas comumente como stickers, podem ser consideradas como um recurso de persuasão. De modo específico, queremos mostrar que os stickers funcionam como expediente de adesão ou não ao que foi exposto/postado, buscando louvar ou criticar algo e, portanto, têm caráter epidítico. A justificativa do estudo deve-se ao fato de tais formas multimodais terem assumido um papel relevante nas conversas digitais contemporaneamente, substituindo, muitas vezes, os textos verbais escritos ou falados, ou seja, as mensagens digitadas ou gravadas em áudio.

Palavras-chave: Sticker. Humor. Retórica. Gênero epidítico.

\begin{abstract}
Based specially on the theoretical assumptions of Rhetoric and New Rhetoric, we intend, in this article, to give thought about certain "figures" used in WhatsApp interaction, which were commonly known as stickers, can be considered as a persuasive resource. Specifically, we want to show that the stickers work as a way of adhering or not to what was exposed/posted, seeking to praise or criticize something and, therefore, have an epidemic character. The justification of the study is that such multimodal forms have assumed a relevant role in contemporary digital conversations, often replacing written or spoken verbal texts, i.e., typed or recorded audio messages.
\end{abstract}

Keywords: Sticker. Humor. Rhetoric. Epidithic genre. 


\section{Considerações iniciais}

Sabemos que há diferentes formas de inserir conteúdo no WhatsApp, rede social que tem ganhado espaço e dado uma nova configuração ao papel exercido pelos "smartphones" na sociedade. O usuário pode escrever algo, incluir vídeos, fotos e até mesmo figuras criadas para estabelecer contato com as outras pessoas. Estas últimas, usadas cada vez com mais frequência, têm sido chamadas de stickers, espécie de "adesivos digitais" bem-humorados que são compostos por elementos imagéticos e /ou verbais e criados por usuários anônimos por meio de aplicativo específico ${ }^{1}$. Esses textos multimodais ${ }^{2}$, que versam sobre variados temas, normalmente têm sido empregados como resposta rápida e descontraída, ou seja, por meio das figuras o usuário manifesta acordo ou não referente a algo que tenha sido postado.

Com base nessas considerações e levando-se em conta que os stickers têm circulado paralelamente aos textos verbais escritos ou falados (neste caso, dos áudios gravados) nas conversas digitais via WhatsApp, e em muitas ocasiões até substituindo tais textos, este artigo busca refletir sobre o papel desse recurso no processo de interação nessa rede social. O objetivo principal é mostrar que tais figuras constituem um recurso persuasivo. De caráter epidítico, servem para louvar ou criticar, funcionando, portanto, como um expediente de adesão ou não ao que foi postado. Desse modo, os pressupostos teóricos adotados na análise dos dados são os de autores da Retórica (ARISTÓTELES, 2015) e da Nova Retórica (REBOUL, 2004; PERELMAN; OLBRECHTS-TYTECA, 2005; MEYER, 2007a, 2007b; TRINGALI, 1988, 2014).

A retórica, segundo Aristóteles (2015), é uma ciência que se ocupa dos princípios e das técnicas de comunicação com fins persuasivos; logo, considera como as pessoas usam a linguagem para alterar percepções, explicar, mudar, reforçar e canalizar uma crença. O discurso retórico se manifesta como a construção de uma argumentação que conduz o auditório (ouvinte/leitor) numa direção, projeta um ponto de vista, busca adesão e, concebe, de modo verossímil, uma determinada representação da realidade.

\footnotetext{
${ }^{1}$ A multimodalidade é entendida aqui como a "característica dos textos cujos significados são realizados por meio de mais de um código semiótico", quando ocorre, portanto, o "entrecruzamento de linguagens - verbal (oral e/ou escrita), visual, sonora" (CAVALCANTE; CUSTÓDIO FILHO; BRITO, 2014, p. 152).

${ }^{2}$ Cf. Congo e Fraga (25 ago. 2013) e Trindade (25 out. 2018).
} 
Se as palavras são revestidas de inúmeros artifícios retóricos para encantarem, persuadirem, dissuadirem, convencerem e, assim, refletirem o saber, o querer e o fazer humanos, entendemos que as imagens também o são. Segundo registram Campbell, Huxman e Burkholder (2015, p. 12):

\begin{abstract}
Imagens que visam nos influenciar são inevitáveis. Escultura, piquete, sinalização e trânsito, símbolos religiosos e políticos, vídeos do YouTube, aplicativos do smartphones, filme, programação de televisão, fotografias, ícones do computador, sites, pinturas, cartazes, anúncios impressos, arquitetura, dança desfiles, logotipos corporativos, cartazes e muitos outros eventos visuais enriquecem e confundem a nossa paisagem simbólica [...]. Considera-se a imagem como mensagem persuasiva integral ou dominante.
\end{abstract}

Em nossos dias, de modo ainda mais intenso do que sempre foi, as mídias sociais valem-se da imagem para disseminar temas ligados ao senso comum. No espaço da doxa fundamentalmente não se discutem verdades e certezas, manifestam-se, na maior parte das vezes, opiniões. Por isso, o movimento persuasivo é dialético: não só permite a discussão de valores, de hierarquias, de preferências, como também conclama deliberação e testa ideais democráticos. Os stickers, consolidados em discursos, têm sido uma das formas de movimento persuasivo. Antes, porém, de mostrarmos como isso funciona, cabe tratar de conceitos retóricos que irão ancorar as bases teóricas para a análise de alguns dos casos desse modo de interação digital.

\title{
1. Retórica e gênero de discurso epidítico
}

A retórica, pensada a priori como a arte de persuadir pelo discurso especificamente verbal, é definida por Aristóteles (2015, p. 62) como a "capacidade de descobrir o que é adequado a cada caso com o fim de persuadir". De acordo com os pressupostos do filósofo, o discurso, concebido como processo comunicativo retórico, compreende três elementos: aquele que fala (o orador), a quem se fala (o auditório) e o assunto de que se fala (discurso). Esses elementos vinculam-se às provas de persuasão, já que estas podem residir no caráter moral do orador (ethos), no modo como se dispõe o auditório (pathos) e no próprio discurso (logos), pelo que se demonstra ou parece demonstrar.

Considerando-se especialmente a natureza do auditório, ou seja, os tipos de ouvintes (mais precisamente pela função que exercem) e a necessidade de 
adaptar-se a eles, Aristóteles, no livro I da Retórica, classifica os gêneros de discursos retóricos ou oratórios, o que chama de "espécies de retórica" (2015, p. 68), em três tipos: o judicial, o deliberativo e o epidítico. A classificação aristotélica - seguida por muitos teóricos nela inspirados - parte de algumas referências, conforme registra Tringali (2014, p. 69):

- A reação do auditório depois de ouvido o discurso

- O objetivo do discurso

- O tempo em que a questão tratada pelo auditório acontece

- O valor visado pelo auditório

Em linhas gerais, por esses critérios, no gênero judicial ou forense, o auditório atua como árbitro, analisa uma causa passada, pondera sobre o justo/injusto, o legal/ilegal, e, a partir da reflexão, julga, visto que condena/acusa ou absolve/inocenta. No gênero deliberativo ou político, depois de ouvido o discurso, o auditório atua como membro de uma assembleia, uma vez que, diante de uma causa que pode vir a acontecer, reflete sobre o útil/nocivo, aconselhando ou desaconselhando a tomada de uma decisão. No gênero epidítico, conhecido também como demonstrativo ou laudatório, o auditório atua como espectador, analisa ou aprecia uma questão como bela/agradável ou feia/desagradável sob a perspectiva da atualidade, buscando louvá-la ou censurá-la.

Ainda no que diz respeito aos critérios que distinguem os gêneros retóricos, é preciso salientar o tipo de argumentação que cada um deles mobiliza. Reboul (2004) faz uma síntese das considerações de Aristóteles (cf. Livro I, 1357 b, 1368 a) que, no nosso entender, merece registro:

O judiciário, que dispõe de leis e se dirige a um auditório especializado, utiliza de preferência raciocínios silogísticos (entimemas), próprios a esclarecer a causa dos atos. $O$ deliberativo, dirigindo-se a um público mais móvel e menos culto, prefere argumentar pelo exemplo, que, aliás, permite conjecturar o futuro a partir dos fatos passados [...]. Quanto ao epidítico, recorre sobretudo à amplificação, pois os fatos são conhecidos pelo público, e cumpre ao orador darIhes valor, mostrando sua importância e nobreza (REBOUL, 2004, p. 46).

Ao tratar do tema sob a ótica da problematologia - uma vez que define retórica como a "negociação da distância entre os homens a propósito de uma questão, de um problema" - Meyer (2007a, p. 27) destaca que a classificação dos gêneros retóricos feita por Aristóteles limita a retórica a três tipos de 
problemática, tendo em vista que as espécies de gêneros definem tanto as questões que são tratadas (isto é, colocadas pelo auditório - ouvintes ou leitores) quanto as respostas guardadas para as indagações postas. Nessa esteira, o filósofo belga diz que "os gêneros retóricos correspondem a uma gradação no tratamento das respostas" (2007a, p. 29). Mas o que significa exatamente isso?

Conforme Meyer (2007a), no gênero deliberativo há uma questão e, consequentemente, uma alternativa (ou várias delas) como resposta; no judiciário, a problemática é reduzida, por haver meios do direito (a lei) para resolvê-la; já no epidítico, "o problema consiste em fazer de tal forma que não haja problema” (2007a, p. 29), ou seja, a questão é praticamente anulada. Para o autor, como sempre somos uma pergunta para o outro, ao afastá-la, reduzse a "distância entre os indivíduos" (esta, retoricamente, deve ser negociada e reduzida). Como o epidítico tende a anular a questão/o problema, cumpre sua finalidade com esmero: diminui a distância entre as pessoas. Ainda a esse respeito, Meyer (2007b, p. 34) comenta que:

Quanto mais uma questão ou uma causa é certa, menos se impõe decidir: louvamos ou desaprovamos, aceitamos ou recusamos. A paixão e a opinião que a acompanha é então único juiz. Pronunciamo-nos em função daquilo que sentimos. Por contraste, quanto mais duvidosa uma questão é, mais precisamos deliberar e menos o outro é depositário de decisão e, assim, somos confrontados ainda mais com uma problematicidade plural que devemos tomar sob nossa responsabilidade sem descanso.

Convém esclarecer que, embora Aristóteles tenha proposto a divisão dos gêneros em três espécies de retórica, ele mesmo registra que frequentemente há sobreposição dos tipos, ou seja, raramente se depara com um discurso puramente epidítico, judicial ou deliberativo, pois os gêneros se misturam em doses diversas. $O$ importante é saber qual predomina em um ato retórico. Desse modo, a divisão não é rígida, somente coloca em evidência o grau de relevância que o orador deve atribuir ao auditório em dado contexto.

Com base nessas considerações, ainda que os stickers possam ser usados como forma de deliberar ou julgar, admite-se a hipótese de que, na maior parte dos casos, eles são empregados como meio de o ouvinte ou leitor (o auditório) louvar ou criticar algo, logo, têm predominantemente caráter epidítico. O fenômeno - a exemplo de diversas outras formas de caráter 
emotivo, caso do epitáfio, poema, conto, comentário - é recoberto pelos discursos de elogio e censura. Em razão do posicionamento assumido, cabe tratar mais detalhadamente desse tipo de gênero retórico.

O termo epidítico (do grego epideiktikós e do latim epidicticu) consiste em um adjetivo que pode remeter tanto ao discurso aparatoso, ostentoso, quanto ao discurso demonstrativo, exemplificativo (cf. FERREIRA, 1999). Ao tratarem-no como gênero oratório, os estudiosos retomam muitas vezes as referências já mencionadas anteriormente.

O gênero epidítico tende a abordar, no que diz respeito ao tempo, uma questão situada no presente. No entanto, como o presente é efêmero, compreende tudo que tem a marca da atualidade; interessa o hoje e o agora (cf. TRINGALI, 1988). Reboul (2004, p. 45) acrescenta que esse gênero se refere ao presente, porque "o orador propõe-se à admiração dos espectadores, ainda que extraia argumentos do passado ou do futuro".

Quanto à forma de atuação, o auditório mostra que concorda ou discorda, que gosta ou não de algo. Como o papel de espectador do auditório é aprovar ou reprovar - pelo ato de louvar, elogiar, exaltar, enaltecer, gabar, falar bem, ou pelo ato de criticar, censurar, repreender, vituperar, vilipendiar, admoestar -, o epidítico exerce profunda influência, visto que busca modificar ou reforçar o quadro dos valores sociais vigentes, sejam eles vistos como virtudes, sejam como vícios. Desse modo, segundo destaca Tringali (2014, p. 71), esse gênero “desperta a reflexão crítica, forma a opinião e dispõe para a ação", o que o torna persuasivo.

Nessa mesma linha, a que considera o gênero epidítico persuasivo, também se posicionam Perelman e Olbrechts-Tyteca (2005). No Tratado da argumentação, os autores dedicam uma seção de cinco páginas sobre o tema. Ao trazerem o assunto em questão, lembram que os discursos de exaltação ou censura (aos quais ninguém se opunha, apenas aplaudia ou ia embora após ouvi-los) eram vistos meramente como "uma forma degenerada de eloquência", cujo objetivo se limitava a "agradar, realçar, ornamentar fatos manifestos ou, pelo menos, incontestes" (PERELMAN; OLBRECHTS-TYTECA, 2005, p. 54). Por entender que o orador sempre visa persuadir o auditório com seu discurso, Aristóteles (2015) vê outra finalidade aos discursos que se 
ocupavam do belo e do vergonhoso, da virtude ou do vício, dando-lhes um papel de relevância.

Não apenas compactuando do raciocínio aristotélico, mas buscando ampliá-lo, Perelman e Olbrechts-Tyteca (2005, p. 54) defendem que "os discursos epidíticos constituem uma parte central da arte de persuadir", pois reforçam uma disposição para ação ao aumentarem a intensidade de adesão às teses apresentadas, aos valores que são exaltados ou censurados. Nesse sentido, como se verifica no excerto que segue, os teóricos destacam que o discurso epidítico é significativo e extremamente importante para a argumentação.

Ao contrário da demonstração de um teorema de geometria, que estabelece de uma vez por todas um vínculo lógico entre verdades especulativas, a argumentação do discurso epidítico se propõe aumentar a intensidade da adesão a certos valores, sobre os quais não pairam dúvidas quando considerados isoladamente, mas que, não obstante, poderiam não prevalecer contra outros valores que viessem a entrar em conflito com eles. O orador procura criar uma comunhão em torno de certos valores reconhecidos pelo auditório, valendo-se do conjunto de meios de que a retórica dispõe para ampliar e valorizar (PERELMAN; OLBRECHTS-TYTECA, 2005, p. 55-56).

Para finalizar este tópico, convém ainda ressaltar que todo discurso retórico, por ser dialético, sempre enseja e provoca um discurso contrário. Todo discurso ou pressupõe um discurso anterior ou prevê um discurso posterior. Teoricamente não deveria haver um discurso sem resposta. No epidítico, como ressalta Tringali (2014), a resposta não é tão urgente, como no judiciário e no deliberativo. No entanto, o fato de não requerer uma contestação imediata não significa que a resposta seja irrelevante.

\section{O caráter epidítico dos stickers}

Para mostrar o caráter epidítico dos stickers em conversas digitais, passemos à análise de dois casos de interação. Um deles remete a uma situação de louvor; o outro, de crítica. Convém registrar, antes, que, em ambas as situações, por uma questão ética, os usurários foram desidentificados por meio de tarjas. Também é preciso ressaltar que as situações epidíticas não se esgotam pelos stickers observados nas interações examinadas: estas servem apenas como amostra do funcionamento do recurso. 


\section{$\mathrm{EI} \sqcap \mathrm{\alpha A}$}

\subsection{Stickers de louvor}

Interação I

Figura 1 - Interação I

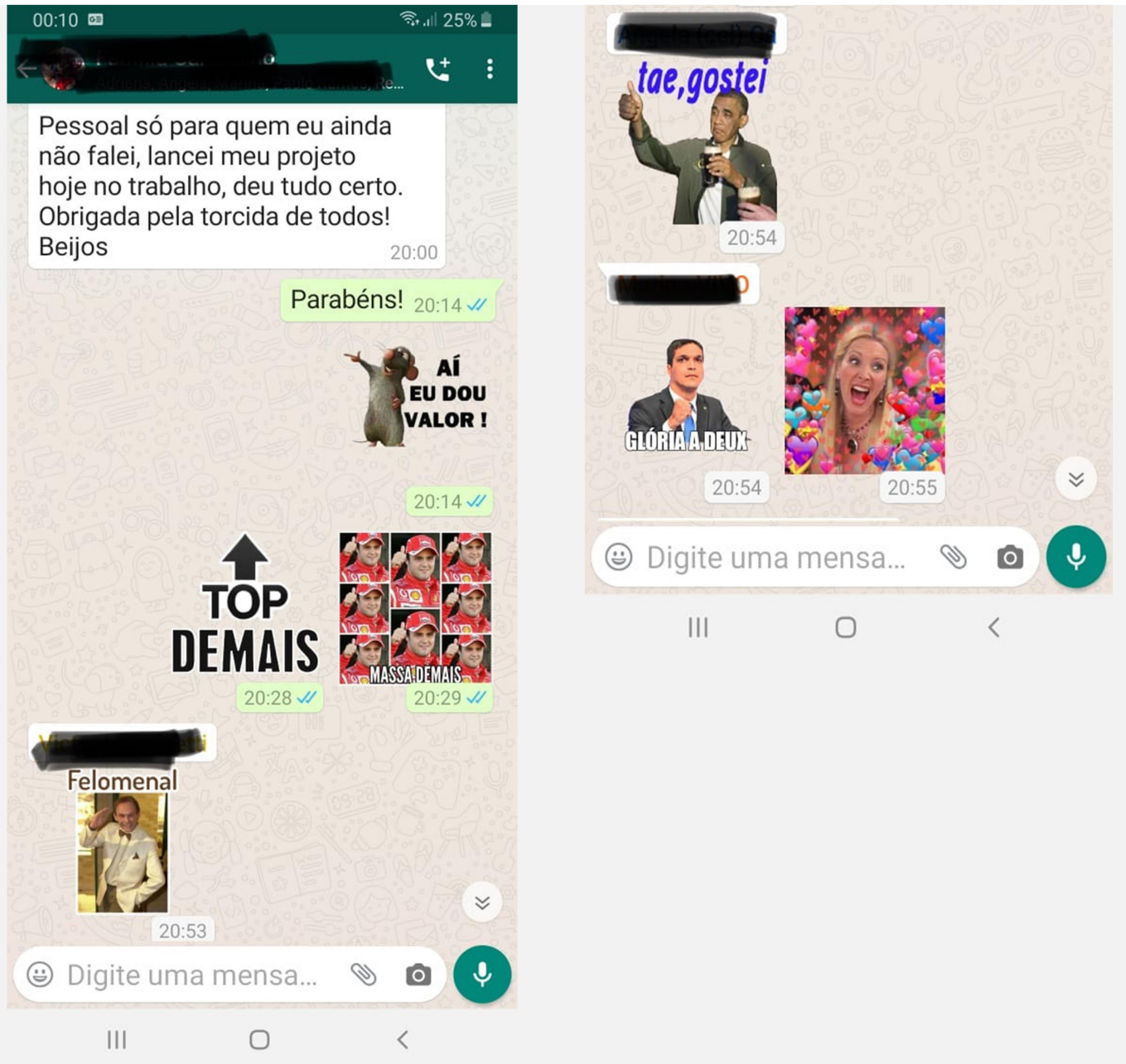

Fonte: Arquivo particular

A título de contextualização, o exemplo I consiste em uma troca de mensagens de um grupo do WhatsApp, no qual quatro pessoas interagem. A conversa digital - que se configura num ato retórico, mobilizando, portanto, em sua construção orador, auditório e discurso - pode ser sintetizada, na sequência em que ocorre, da seguinte forma: 
a) (1) posta uma mensagem verbal escrita, relatando que uma atividade realizada no emprego teve êxito: "Pessoal só para quem eu ainda eu não falei, lancei meu projeto hoje no trabalho, deu tudo certo. Obrigada pela torcida de todos! Beijos" (20:00)

b) (2) comenta a postagem de (1) por meio do enunciado verbal "Parabéns!" (20:14) e de três stickers: o ratinho da animação "Ratatouille" + "AÍ EU DOU VALOR" (20:14), o desenho de uma seta voltada para cima + a expressão "TOP DEMAIS" (20:28) e um painel com oito fotos do piloto de fórmula 1 Felipe Massa + a legenda "MASSA DEMAIS";

c) (3) comenta a postagem de (1) por meio de um sticker: a foto do ator José Wilker + "Felomenal" (20:53);

d) (4) também se manifesta sobre a postagem de (1) por meio de um sticker: a foto de Barack Obama + "tae, gostei” (20:54);

e) (1) responde aos comentários de (2), (3) e (4), numa forma de agradecimento, por meio de dois stickers: a foto de Cabo Daciolo + "GLÓRIA A DEUX" (20:54) e a foto da personagem Phoebe, rodeada por corações coloridos (20:55).

Do excerto que serve como exemplo, merecem destaque dois dados: a) o fato de a comunicação entre os usuários se dar majoritariamente por meio de stickers; b) embora muito diferentes entre si, levando-se em conta a composição e a origem, os stickers usados para comentar a postagem de (1) assumem a mesma função do enunciado verbal "parabéns”, qual seja, louvar. Vejamos cada um deles detalhadamente.

O primeiro sticker foi elaborado a partir do desenho do ratinho Rémy (personagem central do filme "Ratatouille", de 2007, vencedor no ano seguinte do Oscar de melhor animação), mostrado com o rosto e uma das mãos apontados para o lado direito dele (e esquerdo do leitor) e ladeado pela expressão verbal escrita "AÍ EU DOU VALOR”, redigida com letras maiúsculas. Há, no caso, uma mescla de referências. Visualmente, como comentado, tratase de menção ao protagonista do longa-metragem. Verbalmente, no entanto, remete ao bordão empregado por Milene Pavorô (Milene Uehara), assistente de palco do "Programa do Ratinho", exibido pelo SBT (Sistema Brasileiro de Televisão) e que tem como apresentador Carlos Roberto Massa, conhecido pela sua alcunha, Ratinho. A expressão, conhecida como uma das marcas da comediante, busca valorizar uma pessoa, uma atitude ou um acontecimento (cf. PONTTEZ, 18 mar. 2017). 
Ao postar o sticker para enaltecer o ocorrido com (1), (2) vale-se de dois argumentos imbuídos na própria figurinha ${ }^{3}$. Um deles é o argumento de autoridade, tendo em vista que se ampara na expressão de uma pessoa reconhecida (no caso, Pavorô) para validar a intenção. Influenciado pelo prestígio, esse argumento, como atestam Perelman e Olbrechts-Tyteca (2005, p. 347), "utiliza atos ou juízos de uma pessoa ou de um grupo de pessoas como meio de prova a favor de uma tese". O outro é a regra de justiça. Fundamentado na importância de um precedente, o argumento leva em conta, por exemplo, que pessoas sérias, honestas, trabalhadoras merecem ter sua dignidade reconhecida (cf. FERREIRA, 2010). No caso, é justo ter dado certo o lançamento do trabalho de (1) por causa do esforço despendido na causa, daí o destaque de valorização.

O segundo sticker, inserido também por (2), apresenta o desenho de uma seta voltada para cima seguida da expressão "TOP DEMAIS" grafada em caixa alta e na cor preta. A posição da seta indica que o que é caracterizado como "top demais" é algo que foi postado anteriormente, no caso, a mensagem de (1). Considerando-se que a expressão - formada pelo substantivo "top", de origem inglesa, que remete a algo ou alguém no topo, superior, juntamente com o advérbio de intensidade "demais" - significa algo demasiadamente superior, muito bom, nota-se que o sticker funciona, uma vez mais, para louvar o ocorrido.

Além de ser, por si só, um expediente persuasivo, a figurinha traz em sua constituição mais dois recursos retóricos que ajudam a acentuar a apreciação. A hipérbole é um deles, isto é, "o exagero expressivo por aumento ou diminuição" (TRINGALI, 1988, p. 139), tendo em vista que amplifica o status do objeto referido: se tudo que é "top" é bom, superior; “top demais" seria bom em demasia. Ao manifestar, pelo próprio significado, que seja algo muito positivo e superior, a expressão mobiliza o lugar de qualidade, visto que valoriza o raro, o único, o original (cf. FERREIRA, 2010): ser "top demais" não seria um evento muito comum.

Construído nos moldes de um painel de fotografias, o terceiro sticker [o terceiro e último publicado por (2)] exibe oito fotos iguais do piloto de

3 A partir deste momento, utilizaremos a palavra "figurinha" como forma sinônima para sticker. 
fórmula 1 Felipe Massa, fazendo o sinal de positivo com o polegar direito. Automobilista brasileiro, ele foi vice-campeão mundial em 2008. Abaixo das imagens, sob a forma de legenda, tem-se a frase "MASSA DEMAIS", grafada em caixa alta. A expressão - composta pelo termo "massa" e o advérbio de intensidade "demais" - é utilizada para caracterizar algo considerado muito bom, legal, surpreendente, admirável.

A associação da palavra a uma sequência de fotos do piloto pode ser lida de dois modos, daí a produção do humor: a) "Massa" é lido como um nome (substantivo próprio) e, portanto, haveria em demasia pelo fato de a montagem contemplar oito fotos dele; b) "massa" pode ser interpretado como um vocabulário gírio [que significa "ótimo", "coisa muito boa" (cf. SERRA E GURGEL, 1998, p. 307)], conotando que o corredor de fórmula 1 seja extremamente bom. A grafia das palavras em letras maiúsculas - em particular a primeira, "MASSA" - ajuda a reforçar a ambiguidade aos olhos do leitor. Isso porque não fica claro se se trata do sobrenome (que deveria iniciar com caixa alta) ou da gíria (em minúsculas). Como, no entanto, o sticker é usado como recurso para comentar a postagem de (1), buscando exaltá-la, a leitura pretendida por (2) tende a ser a extraída da expressão gíria.

Assim como nos demais casos, o sticker também mobiliza em sua construção duas figuras retóricas que reforçam o elogio. A hipérbole, ou seja, o aumento da intensidade semântica, pode ser vista na amplificação do status de "MASSA" tanto na expressão verbal escrita, pelo advérbio de intensidade "demais", quanto na linguagem visual, pela repetição das fotos do piloto. Outra figura observada é a epizeuxe, que significa encadeamento. Usado para se referir à "repetição seguida da mesma palavra" (TRINGALI, 1998, p. 129), entendemos que o recurso pode ser transposto também à imagem, já que, no caso em questão, tem-se a repetição seguida da mesma foto de Felipe Massa, ainda que em cortes distintos (três colunas de fotos, sendo que a do meio apresenta duas fotos maiores e as colunas laterais, três menores), com a finalidade de exortar, enfatizar o sentido nelas contido (Massa demais).

Os dois próximos stickers da interação, como explicitado, foram postados por integrantes distintos, (3) e (4), respectivamente. Para enaltecer o ocorrido com (1), o lançamento de um projeto bem-sucedido no trabalho, (3) posta uma figurinha formada pela foto de José Wilker, acompanhado da 
palavra “Felomenal”. Essa vinculação leva o leitor a entender que a referência não seja propriamente ao ator, mas a um de seus personagens mais populares e lembrados: Giovanni Improtta, vivido por ele na novela "Senhora do Destino", produzida em 2004 pela Rede Globo e reexibida em 2017. "Felomenal" era uma de suas mais célebres expressões e correspondia ao adjetivo "fenomenal".

Conhecido pela inseparável gravata borboleta (como mostrado na foto reproduzida no sticker) e pelo esforço (não bem-sucedido) para falar conforme a norma padrão culta, o personagem cometia vários mudanças na pronúncia das palavras. "Felomenal", a exemplo, em que ocorre a troca da consoante "n" por "l”, embora consista numa forma não padrão do português, ilustra um fenômeno fonético bastante comum, visto tanto na construção da língua portuguesa ("livel”, do latim livellu, virou “nível”) quanto em uma de suas modalidades, o dialeto rural ("animal"> "alimá") 4 . Na boca do personagem - empregado de modo bem-humorado para se referir a algo raro, surpreendente, espantoso, admirável -, o termo funciona como expediente retórico. É, portanto, a seleção lexical a responsável por categorizar positivamente, louvando.

O sticker postado por (4) como meio de comentar o relato de (1) traz a imagem de Barack Obama juntamente à expressão "tae, gostei". O político foi flagrado várias vezes tomando uma cerveja em compromissos oficiais e sociais durante o período em que esteve à frente da presidência dos Estados Unidos (2009-2017). A página de notícias do "News One" chegou a fazer um ranking dos 15 melhores momentos em que foi flagrado bebendo. Um dos registros é o utilizado para a composição do sticker. O primeiro afro-americano a comandar o país é mostrado fazendo um gesto de positivo com a mão direita. $\mathrm{Na}$ outra, segura um copo de cerveja. A legenda, no alto da foto, aportuguesa o tema por meio da expressão "tae, gostei", utilizada em situações de manifestação à uma notícia boa, um acontecimento legal. "Tae" é uma redução de "está aí" e sugere aprovação a algo. O gesto de positivo de Obama

\footnotetext{
${ }^{4}$ Para maiores informações sobre o fenômeno fonético, conhecido como lateralização, no qual a consoante "n" é trocada por "l" - caso possível pelo fato de ambas serem alveolares e, portanto, terem o mesmo ponto de articulação -, consultar Bollela, Faleiros e Guedes Filho (2007).

${ }^{5}$ Disponível em: https://newsone.com/playlist/barack-obama-beer-moments/item/1. Acesso em: 20 dez. 2019.
} 
corrobora isso. Convém destacar que, para enaltecer algo, o sticker se vale do argumento de autoridade, visto que faz uso da figura do ex-presidente Obama para validar um propósito.

Para interagir com as postagens de apoio de (2), (3) e (4) bem como para celebrar o fato de seu projeto ter dado certo, (1) também se utiliza de stickers, no caso, dois. Integram o primeiro deles uma imagem do Cabo Daciolo e a expressão verbal "GLÓRIA A DEUX", escrita com letras maiúsculas. A compreensão da figurinha requer conhecimento dos fatos que levaram à sua origem. A eleição presidencial brasileira de 2018 iniciou com 14 candidaturas que, depois, reduziram-se para 13. Uma delas era de Cabo Daciolo, que pontuava seus discursos com alusões religiosas. Nessas falas, tornou conhecida a expressão "glória a Deus".

Deputado federal eleito pelo Rio de Janeiro, ele trazia na pronúncia um sotaque próprio do estado que lhe deu o cargo. O "s" final de "Deus" é dito como uma $(\Omega$. Para se referirem à palavra, usuários da internet começaram a caracterizá-la de um modo bem-humorado com um " $x$ " no final, letra que se assemelha à pronúncia. A junção disso gerou a construção "glória a Deux", a mesma reproduzida no sticker, logo abaixo de uma foto do político. Sinônimo de "aleluia", a construção é empregada para expressar sentimentos de conquistas, quando algo desejado acontece; desse modo, vale-se do argumento de superação, o qual exalta a finalidade, a possibilidade de ir sempre mais longe num certo sentido, aludindo à superação de uma expectativa (cf. PERELMAN; OLBRECHTS-TYTECA, 2005).

O sticker final traz em cena a imagem de Phoebe, envolvida por corações coloridos. A personagem é interpretada pela atriz norte-americana Lisa Kudrow e foi vivida por ela no seriado "Friends". Bastante popular, com dez temporadas exibidas entre 1994 e 2004, a série mostrava as relações de um grupo de seis amigos. Phoebe tinha como marcas a alegria, a criatividade e a espontaneidade, manifestadas em respostas e atitudes inesperadas e, não raras vezes, fora do comum. A vinculação com "Friends" leva o sticker a representar exaltação e euforia, próprias da personagem (e não necessariamente da atriz), que podem conotar vibração e/ou comemoração pela história com final bem-sucedido de (1). Nesse sentido, ao recorrer ao argumento de autoridade, por se apropriar da imagem de Phoebe, o sticker 


\section{$\mathrm{EI} \sqcap \mathrm{\alpha A}$}

Revista Eletrônica de Estudos Integrados em Discurso e Argumentação, Ilhéus, n. 20, v. 1, 2020.

busca revelar certa identificação entre a celebridade e o usuário que se manifesta por meio dela.

\subsection{Stickers de crítica}

Interação II

Figura 2 - Interação II

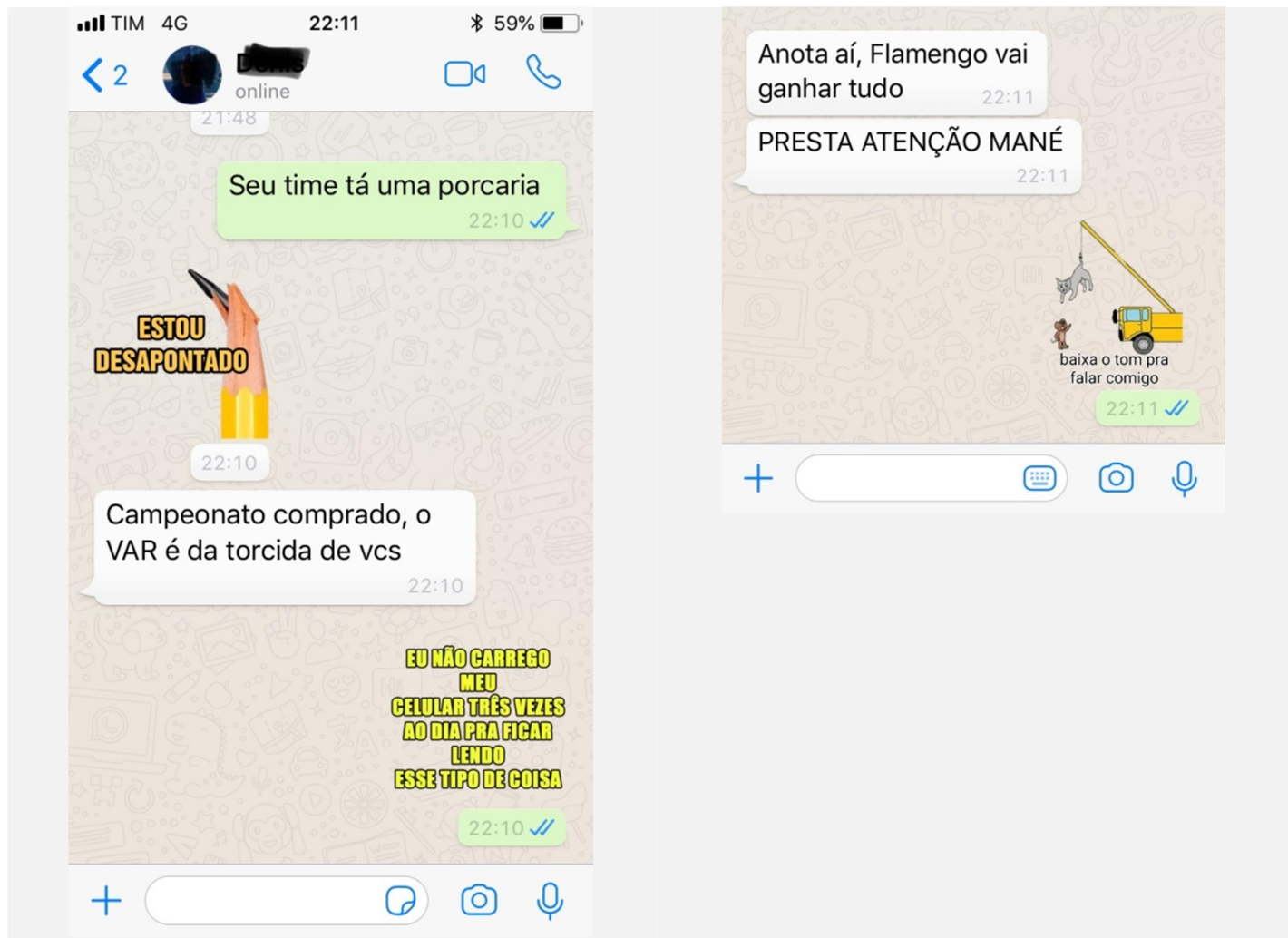

Fonte: Arquivo particular

A segunda interação a ser analisada foi realizada entre duas pessoas e durou dois minutos (entre as 22:10 e as 22:11, horas que aparecem embaixo de cada um dos registros feitos). O contato tem a seguinte sequência:

a) (1) registra uma mensagem verbal escrita, afirmando que a equipe para a qual (2) torce (descobre-se depois que o esporte em questão é o futebol) passa por um momento ruim: "Seu time tá uma porcaria" (22:10);

b) (2) apresenta duas respostas, ambas inseridas no mesmo minuto (22:10); a primeira é um sticker de um desenho de lápis, com a ponta quebrada + o 
enunciado "ESTOU DESAPONTADO"; a segunda é verbal: "Campeonato comprado, o VAR e da torcida de vcs";

c) a réplica de (1) é feita por meio de três enunciados, o primeiro inserido às 22:10 e os demais, no minuto seguinte: "EU NÃO CARREGO MEU CELULAR TRÊS VEZES AO DIA PRA FICAR LENDO ESSE TIPO DE COISA"; "Anota aí, Flamengo vai ganhar tudo"; "PRESTA ATENÇÃO MANÉ";

d) (2) responde com um sticker com os personagens do desenho animado Tom e Jerry, em que o primeiro é mostrado suspenso pelo guindaste de um caminhão + o enunciado "baixa o tom pra falar comigo" (22:11).

O diálogo digital tem início com o que parece ser uma provocação à equipe de futebol para a qual torce (2): "Seu time tá uma porcaria". Desqualificações assim, feitas em tom de deboche e tendo esse esporte como tema, fazem parte da cultura do brasileiro em situações informais de fala. A resposta de (2) é dada por intermédio de um sticker e, depois, por uma frase. O sticker reproduz o desenho de um lápis, com a ponta quebrada. Ao lado, aparece a expressão "ESTOU DESAPONTADO", que tem seu sentido inicial modificado após a vinculação com a imagem. Em vez conotar um desapontamento, uma frustração sobre algo, passa a se referir ao que é exposto visualmente, ou seja, a um instrumento de escrita sem a ponta, como mostrado. O humor construído vem dessa relação literal entre o que é escrito e o que é mostrado. Para manifestar a desaprovação ao que havia sido dito, o sticker mobiliza em sua constituição a figura da ambiguidade, vista a partir do duplo sentido gerado pela expressão verbal escrita e imagem: tendo em vista que "estar desapontado" pode remeter ao fato de um lápis estar sem ponta ou ao estado emocional de decepção.

Após o sticker, aparece a segunda resposta dada por (2), feita apenas verbalmente: "Campeonato comprado, o VAR é da torcida de vcs". Essa afirmação, de certa forma, devolve a provocação recebida: a derrota do time não teria sido justa; por esse ponto de vista, teria havido irregularidades no torneio (pessoas envolvidas nas partidas teriam sido "compradas" - termo que faz alusão, um figura retórica, ao ato de suborno - para interferirem nos resultados finais), sendo uma delas a atuação dos juízes que atuam na observação dos jogos por meio de monitores (processo conhecido como VAR, sigla para "video assistant referee"). 
Na sequência, (1) retoma o diálogo respondendo aos dois comentários anteriores por meio de um sticker composto apenas pelo enunciado verbal escrito "EU NÃO CARREGO MEU CELULAR TRÊS VEZES AO DIA PRA FICAR LENDO ESSE TIPO DE COISA". Hiperbólico (posto que não haveria a necessidade de pôr carga tantas vezes no aparelho em um período tão curto de tempo), o trecho desqualifica o argumento anterior (afinal, tudo o que fora lido teria sido perda de tempo). A figurinha usada como forma de manifestar crítica traz em sua constituição alguns expedientes retóricos: a figura da hipérbole, que remete ao exagero, e o lugar de quantidade, que se utiliza de números para persuadir. Nesse caso, a quantidade de vezes em que o celular é carregado ao dia, três vezes, leva à hipérbole, ou seja, à superlatividade do enunciado.

É somente na resposta seguinte de (2) que se descobre, enfim, a qual time de futebol se está fazendo referência: "Anota aí, Flamengo vai ganhar tudo". À menção à equipe de futebol do Rio de Janeiro, segue-se outro enunciado: "PRESTA ATENÇÃO MANÉ". Redigido em maiúsculas, ele conota tonalidade de fala mais alta nas representações prosódicas adotadas na internet. Por isso, e principalmente pelo conteúdo apresentado (posto que houve registros anteriores que não indicaram essa interpretação), sugere também algo mais do que uma provocação, funciona quase como um alerta, uma ameaça (mesmo que velada) para que (1) não faça mais comentários como os feitos. Uma forma de criticar. Soma-se a isso a utilização da gíria “mané”, que significa "bobo, palerma” (cf. SERRA E GURGEL, 1998, p. 303) e adquire aspecto depreciativo, desqualificador. Outro meio de vilipendiar.

Confirma-se essa leitura de alerta/ameaça ao se observar o comentário seguinte feito por (2). Exposto na forma de sticker, ele apresenta elementos verbais e visuais. O verbal é explicitado no enunciado imperativo "baixa o tom pra falar comigo", ou seja, depreendeu-se que teria havido uma intenção de o trecho anterior ser manifestado em tonalidade mais alta de voz (algo que, em uma interação oral, pode ser visto como estratégia de poder sobre a fala do outro, desvalorizando a pessoa e/ou o conteúdo dito por ela). Na prática, busca-se repreender (1) pela atitude de ter elevado a "voz", representada por meio da caixa alta. 
Esse sentido é mantido, mas é modificado ao ser confrontado com as imagens expostas. Assim como no exemplo anterior, trabalha-se para reforçar literalmente o que é dito pela frase. Abaixar o tom, nesse novo contexto, é pôr no solo o gato "Tom", que é mostrado erguido pelo guindaste de um caminhão. E quem diria a frase exposta, pelo menos é o que se sugere, é o camundongo Jerry. Para que essa interpretação seja possível, como comentado na descrição do diálogo, cabe ao leitor depreender que a dupla estabelece um diálogo intertextual com o desenho animado "Tom e Jerry", protagonizado pela dupla. Se reconhecidos por meio de seus traços característicos, tanto imagéticos quanto plásticos (a cor cinza do gato e a amarronzada do rato), constrói-se a proposta humorística do sticker, mesmo que inserida em uma situação de possível embate/tensão. Além de funcionar como argumento, o sticker traz um raciocínio apodítico, uma vez que se coloca como imperativo, autoritário.

Atuando ora como auditório (quando vê/lê mensagens), ora como orador (quando posta mensagens), quem utiliza das conversas via WhatsApp se vale de recursos midiáticos contemporâneos para fazer ecoar suas ideias, manifestar um ponto de vista, posicionar-se, enfim, reagir. Ao considerarmos especificamente o funcionamento dos stickers usados nas interações digitais, se observadas as interações I e II, não há dúvida de que elas têm caráter epidítico. Retomemos os casos e os principais elementos que caracterizam esse gênero oratório.

As questões a que os stickers se reportam, nos dois casos de interação, situam-se no tempo presente. Frisa-se um presente bastante efêmero, tendo em vista que as interações se dão no mesmo dia e se esgotam em minutos. Em I, a conversa travada entre quatro integrantes do grupo ocorre em 6 de janeiro de 2019, tem início às 20:00, com o relato de (1) de que havia lançado seu projeto naquele dia e que tinha dado certo, segue com comentários e se encerra às 20:54. Já em II, nota-se que o tempo de interação entre duas pessoas que discutem sobre futebol, mais precisamente sobre qual time é melhor ou vencerá o campeonato, é de apenas dois minutos.

Essa variação na duração dos contatos está relacionada a uma série de fatores, como o tema discutido, os rumos criados pela conversa, a demanda de respostas gerada, uma eventual situação mais emotiva ou polêmica 
estabelecida. Ou seja: há diferentes elementos que podem interferir no tempo dedicado pelas pessoas à interação (e ao uso de certos stickers) sobre a questão. Embora o foco aqui não seja trabalhar especificamente esse aspecto, cabe ao menos registrar a existência dele e o vínculo às motivações plurais que o explicam.

Ainda sobre as questões abordadas em I e II, por serem certas e não demandarem decisões, os stickers usados pelos usuários que atuam como auditório (e que, portanto, assumem estritamente a função de espectador) servem para apreciá-las ou não, tendo em vista que se pronuncia por meio das figurinhas em função do que se sente. Em I, verifica-se que (2), (3) e (4) reagem à postagem de (1) utilizando-se de stickers para manifestar apoio e admiração. Conforme mostrado, diferentes figurinhas são usadas para louvar e enaltecer o ocorrido com (1). No caso de II, por outro lado - em que se constrói uma interação um pouco mais tensa, possivelmente por causa do tema abordado, que movimenta posições e paixões distintas -, observa-se que tanto (1) quanto (2) se utilizam de stickers para criticar, repreender, admoestar um ao outro, num movimento de desaprovação. Em síntese, verifica-se que o recurso pode condensar dois discursos: exaltação e censura.

Em termos de argumentação, se o gênero epidítico recorre à amplificação, como bem registra Reboul (2004), podemos dizer que os stickers, por terem caráter epidítico, também tendem a amplificar os fatos a que se referem, mostrando com certo exagero sua importância ou insignificância. A amplificação, não custa lembrar, é uma figura que consiste em desenvolver particularidades de um assunto, engrandecendo-os; tem a função de intensificar as ações e colocar o objeto amplificado em posição de superioridade.

Ademais, cumpre destacar que os stickers valem-se, em sua constituição, de um conjunto de meios de que a retórica dispõe - seleção lexical, figuras retóricas, lugares e argumentos - para reforçar e validar sua intenção e funcionamento como recurso persuasivo. Nos exemplos das interações I e II, vimos que, além de figuras como hipérbole, epizeuxe e ambiguidade, foram mobilizados argumentos de autoridade, de superação, a regra de justiça, os lugares de qualidade e de quantidade e a seleção lexical. 
No nosso entender, os stickers servem de recurso de presença, ou seja, procedimento que atua de modo direto sobre a nossa sensibilidade e que tem por objetivo ilustrar a tese que se quer defender. De acordo com Perelman e Olbrechts-Tyteca (2005, p. 135-136), "toda argumentação é seletiva”, supõe uma escolha, que consiste não só na seleção dos elementos que são utilizados, mas também na técnica de torná-los presentes. As figurinhas são argumentos prontos, que podem ser usados para exprimir um ponto de vista sobre situações muito diferentes. Se, segundo os autores, "para cada auditório existe um conjunto de coisas admitidas que têm, todas, a possibilidade de influenciar-lhes as reações, um sistema de referência que serve para testar as argumentações" (PERELMAN; OLBRECHTS-TYTECA, 2005, p. 133), podemos considerar que os stickers constituem esses elementos, levando-se em conta especialmente as conversas digitais via WhatsApp. Por despertarem a atenção assim que disparados e visualizados - seja pelo aspecto multimodal, pelo ar inovador, pelo humor peculiar e por condensar informações numa forma pequena -, são um meio de tornar presente um ponto de vista com muita rapidez. São um argumento pronto e prático, esperando apenas a situação para ser usado.

Como recurso persuasivo de caráter epidítico, podemos dizer ainda que os stickers são significativos e muito importantes para a argumentação, pois reforçam uma disposição para ação ao aumentarem a intensidade de adesão a certos valores que são exaltados ou censurados. Nesse sentido, as figurinhas têm o potencial de provocar um impacto sobre a vida da(s) pessoa(s) integrada(s) àquela rede de contato(s), afetando decisões. É muito fácil percebermos isso se retomarmos a interação I. Ao comentar a postagem de (1), enaltecendo o ocorrido por meio de três stickers, (2) estabelece o tom e acaba influenciando outros integrantes do grupo, no caso (3) e (4), a agirem daquela forma, na mesma direção. A ação de louvar é reforçada e aderida coletivamente pelo auditório. Cria-se uma espécie de comunhão em torno de certos valores reconhecidos entre os usuários. Os stickers, pelo caráter epidítico, não necessariamente ditam uma escolha, mas certamente orientam escolhas. 


\section{Considerações finais}

O WhatsApp é uma rede social que tem modificado a função dos contatos por meio de telefones celulares. Renomeados de "smartphones", os aparelhos permitem, com o auxílio dessa rede social, mais de um tipo de interação entre as pessoas (por áudio, por fotos, por vídeos, por escrito, por imagens gráficas, entre elas os stickers). É comum, em muitos dos casos, haver o uso de mais de um recurso, acarretando uma mescla de modalidades. Foram justamente essas as situações vistas nas interações I e II aqui analisadas.

A reflexão aqui proposta foi sustentada exclusivamente por conceitos de teóricos tratados sob a ótica da Retórica e da Nova Retórica. O principal deles, que norteou as análises, foi o discurso epidítico. Para desenvolvê-la, foi considerada, em termos metodológicos, a análise de dois casos de interação digital a fim de mostrar como essa estratégia retórica se manifesta. Essas duas interações selecionadas consistem apenas numa mostra de como esse novo recurso tem caráter epidítico, já que funciona para registrar comentários de forma elogiosa ou crítica.

Esse recurso tem sido frequentemente utilizado nas interações digitais via WhatsApp, a ponto de substituir as mensagens verbais escritas e faladas. Os stickers - que chamam a atenção pelo aspecto multimodal, pelo humor, pela rapidez e por condensar informações - funcionam em muitas situações como argumentos prontos, à espera de serem acionados conforme a situação demandada pela interação estabelecida. Trata-se de um expediente midiático contemporâneo que faz ecoar uma ideia, um ponto de vista que convence ou persuade, agrega, desagrega ou, até, manipula os menos atentos às artimanhas do discurso. Portanto, como dito, tem caráter epidítico.

Os stickers mostram/refletem o caráter operativo, fluido, vigilante, arrojado (às vezes audacioso) que caracteriza o ato de argumentar nas redes sociais. E rápido também. Para pensar, escrever e clicar para o mundo bastam poucos segundos. A velocidade das postagens, então, reflete o sensível imediato. Os segundos de autoria podem se transformar em horas e horas de comentários ligados a relações racionais ou irracionais de um evento manifestado publicamente por um orador. Este, ao dividir suas impressões sobre os mais variados temas, de ordem pessoal ou não, pode suscitar do auditório uma posição de aprovação ou reprovação. 


\section{Referências}

ARISTÓTELES. Retórica. Tradução: Manuel Alexandre Júnior, Paulo Farmhouse Alberto e Abel do Nascimento Pena. São Paulo: Folha de S. Paulo, 2015. (Coleção Folha, grandes nomes do pensamento, 1).

BOLLELA, Maria Flávia de Figueiredo Pereira; FALLEIROS, Sara Pini; GUEDES FILHO, José Moreira. Oralidade e humor: "O causo da bicicleta". Multiciência, São Carlos, v. 8, p. 168-183, 2007.

CAMPBELL, Karlyn Kors; HUXMAN, Susan Schultz; BURKHOLDER, Thomas Robert. Atos de retórica: para pensar, falar e escrever criticamente. Tradução: Marilena S. S. Garcia. São Paulo: Cengage Learning, 2015.

CAVALCANTE, Mônica Magalhães; CUSTÓDIO FILHO, Valdinar; BRITO, Mariza Angélica Paiva. Coerência, referenciação e ensino. São Paulo: Cortez, 2014.

CONGO, Mariana; FRAGA, Nayara. Stickers são uma nova forma de comunicação. 0 Estado de São Paulo, 25 ago. 2013. Disponível em: https://link.estadao.com.br/noticias/geral,stickers-sao-nova-forma-decomunicacao,10000033083. Acesso em: 20 dez. 2019.

FERREIRA, Aurelio Buarque de Holanda. Novo Aurélio Século XXI: o dicionário de língua portuguesa. 3. ed. rev. e ampl. Rio de Janeiro: Nova Fronteira, 1999.

FERREIRA, Luiz Antonio. Leitura e persuasão: princípios de análise retórica. São Paulo: Contexto, 2010.

MEYER, Michel. A retórica. Tradução: Marli M. Peres. São Paulo: Ática, $2007 a$.

MEYER, Michel. Questões de retórica: linguagem, razão e sedução. Tradução: António Hall. Lisboa: Edições 70, 2007b.

PERELMAN, Chaïm; OLBRECHTS-TYTECA, Lucie. Tratado da argumentação: a nova retórica. Tradução: Maria E. G. G. Pereira. 2. ed. São Paulo: Martins Fontes, 2005.

PONTTEZ, Andreh. Milene Pavorô rouba a cena no Programa do Ratinho. Coluna da TV, 18 mar. 2017. Disponível em: https://colunadatv.com/2017/03/milene-pavoro-roubacena-no-programa-do-ratinho.html/. Acesso em: 20 dez. 2019.

PRETI, Dino. O vocabulário oral popular: a gíria. In: PRETI, Dino. Estudo de língua oral e escrita. Rio de Janeiro: Lucerna, 2004. p. 65-113.

REBOUL, Olivier. Introdução à retórica. Tradução: Ivone C. Benedetti. São Paulo: Martins Fontes, 2004. 
SERRA E GURGEL, João Bosco. Dicionário de gíria - Modismo linguístico - $\mathrm{O}$ equipamento linguístico falado brasileiro. 5. ed. Brasília: Ed. do autor, 1998.

TRINDADE, Rodrigo. Figurinhas começam a chegar no WhatsApp; veja como usar, Uol, 25 out. 2018. Disponível em: https://noticias.uol.com.br/tecnologia/noticias/redacao/2018/10/25/figurinhascomecam-a-chegar-no-whatsapp-veja-como-usar.htm. Acesso em: 20 dez. 2019.

TRINGALI, Dante. A retórica antiga e as outras retóricas: a retórica como crítica literária. São Paulo: Musa Editora, 2014.

TRINGALI, Dante. Introdução à retórica: a retórica como crítica literária. São Paulo: Duas Cidades, 1988.

\section{Forma de citação sugerida}

CARMELINO, Ana Cristina; KOGAWA, Lídia. Stickers do Whatsapp: (nova) forma persuasiva de interação bem-humorada. EID\&A - Revista Eletrônica de Estudos Integrados em Discurso e Argumentação, Ilhéus, n. 20, v. 1, p. 6-27, 2020. DOI 10.17648/eidea-20-v1-2589. 